\title{
Traçando o perfil dos commuters no Brasil
}

\author{
Luiz Carlos Day Gama* \\ André Braz Golgher ${ }^{\star *}$
}

O objetivo deste artigo é a construção de tipologias para os trabalhadores brasileiros, em especial, com relação ao tempo de deslocamento até o trabalho. A partir do método GoM (Grade of Membership), estabeleceram-se perfis puros e mistos de trabalhadores no mercado de trabalho brasileiro, com utilização dos dados das PNADs de 2009 e 2014. Três características básicas marcaram aqueles que gastam bastante tempo comutando: sexo masculino, residentes em áreas metropolitanas e em baixa posição socioeconômica. Analisando o extremo oposto, mulheres em baixa posição socioeconômica são mais presentes em perfis caracterizados por alta prevalência de trabalhadores que nada comutam. A distribuição espacial da população, como esperado, não se dá de forma aleatória. Resumindo, os mais pobres tendem a residir longe do centro e o oposto para os indivíduos em melhor situação financeira.

Palavras-chave: GoM. Comutação. Perfil.

\footnotetext{
*Faculdades Ibmec, Belo Horizonte-MG, Brasil (luiz.gama@ibmec.edu.br; https://orcid.org/0000-0001-7026-2709).

${ }^{\star \star}$ Centro de Desenvolvimento e Planejamento Regional (Cedeplar), Universidade Federal de Minas Gerais (UFMG), Belo Horizonte-MG, Brasil (agolgher@gmail.com; https://orcid.org/0000-0001-5884-225X).
} 


\section{Introdução}

A discussão acerca da importância do tempo de deslocamento diário do indivíduo até o trabalho não é exatamente nova (DUBIN, 1991; GIULIANO; SMALL, 1993; CAMAGNI; GIBELLI; RIGAMONTI, 2002), porém, no Brasil, tem sido negligenciada até recentemente. Um exemplo é o fato de a questão ter sido abordada pela primeira vez em um Censo Demográfico apenas em 2010. Na Pesquisa Nacional por Amostra de Domicílios (PNAD), a investigação começou em 2001, com o questionamento sobre o tempo gasto no trajeto de ida de casa para o trabalho diariamente, mas a indagação sobre a posse de veículo automotor no domicílio, para uso pessoal, foi introduzida apenas em 2009. Além disso, não há nas PNADs e nem nos Censos Demográficos questionamento sobre o modo de transporte utilizado diariamente.

Com as modificações observadas nos últimos anos, tanto na estrutura das cidades quanto no funcionamento do mercado de trabalho, observou-se um aumento do tempo comutado médio, principalmente nos grandes centros (PEREIRA; SCHWANEN, 2013). Além disso, o crescimento da inserção feminina no mercado de trabalho gera implicações sobre a alocação de tempo, inclusive com relação à comutação e participação da mulher na família e na sociedade (LEONE; BALTAR, 2008; HOFFMANN; LEONE, 2009).

0 presente trabalho tem como principal objetivo traçar perfis dos commuters ${ }^{1}$ no Brasil, com foco em residentes em áreas urbanas e com idade entre 21 e 65 anos. Para tanto, são desenvolvidas tipologias de comutação.

Para a criação das tipologias, utilizou-se o método Grade of Membership (GoM), que pode ser traduzido como grau de pertencimento, sendo baseado na teoria dos conjuntos nebulosos. Uma vantagem do método proposto é que ele parte dos próprios dados para a captação e definição dos perfis, tendo por referência a heterogeneidade individual presente na base de dados (TOLLEY; MANTON, 1992).

A seguir, apresenta-se a revisão da literatura sobre o tema. Posteriormente é descrita a estratégia metodológica e discutem-se os resultados. Por fim, são tecidas as considerações finais do trabalho.

\section{Revisão da literatura}

Comutação pode ser medida de diversas formas, mas basicamente é definida como o tempo/distância gasto de casa até o trabalho, diariamente. Tempo comutado é a variável-chave do presente trabalho. Nesse sentido, indaga-se: qual é a importância do componente tempo nos custos de transportes e sobre o bem-estar do trabalhador? Como afirma Brueckner (2011), quando pensamos na função utilidade de um indivíduo, consideramos o tempo que este aloca no trabalho, e a inclusão do custo com a perda de tempo comutando,

\footnotetext{
${ }^{1}$ Commuter é o termo em inglês que designa uma pessoa que viaja determinada distância para trabalhar, com regularidade. A opção pela utilização do termo inglês deve-se ao fato de sua tradução não ser disseminada no Brasil.
} 
além do tempo de lazer. A lógica é simples: uma longa comutação leva a uma redução do tempo disponível para lazer e trabalho, gerando uma perda a este trabalhador.

Com relação ao trabalho, são diversos os fatores que afetam a inserção diferenciada de trabalhadores no mercado de trabalho, provocando, por consequência, impactos na comutação diária entre residência e trabalho. São amplamente estudados e apontados pela literatura sobre mercado de trabalho os diferenciais de rendimentos entre homens e mulheres (LEME; WAJNMAN, 2000; BARROS et al., 2001; LEONE; BALTAR, 2006; MADALOZZO, 2010; HAUSSMANN; GOLGHER, 2016). De maneira geral, os resultados convergem no sentido de que os diferencias existem, em favor dos homens, porém têm diminuído nos últimos anos.

As tarefas do lar são apontadas por alguns autores como parte da causa dos diferenciais de rendimentos entre homens e mulheres. Além disso, o mercado de trabalho brasileiro é historicamente marcado por discriminação e segregação quando o assunto é raça. Apesar disso, a literatura econômica sobre o tema ganhou maior importância apenas a partir do final da década de 1990 e início dos anos 2000. Henriques (2001) traçou o perfil das desigualdades raciais no Brasil e sua evolução ao longo da década de 1990, utilizando dados das PNADs. 0 autor mostrou que, em 1999, os negros correspondiam a $45 \%$ da população brasileira, mas representavam $64 \%$ dos pobres e $69 \%$ dos indigentes.

Por fim, outro fator que contribui para diferenças na inserção do trabalhador no mercado de trabalho e, também, na posição na ocupação refere-se às diferenças educacionais. Segundo Ferreira et al. (2000), “o mercado de trabalho desempenha função importante na amplificação da desigualdade educacional, ao transformá-la em desigualdade de renda, e, além disso, gera novas desigualdades por meio de sua própria segmentação e da existência de discriminação empregatícia”.

Stutzer e Frey (2008) mostram que trabalhadores que gastam muitas horas na comutação reportam menores níveis de bem-estar. Van Ommeren e Puigarnau (2011) encontraram um efeito negativo da longa comutação sobre a produtividade do trabalhador. Fu e Viard (2014) observaram que maior tempo comutado resulta em menos horas trabalhadas. Hymel (2009) argumenta que uma relação negativa entre custos com comutação e horas trabalhadas ajudaria a explicar a relação positiva entre investimentos em transportes e crescimento do emprego no longo prazo.

Achados gerais de estudos empíricos indicam que: comutação decresce à medida que o indivíduo envelhece (CAMSTRA, 1994); pessoas educadas tendem a comutar maiores distâncias (ROUWENDAL; RIETVELD, 1994); estabilidade residencial (WHITE, 1986) e no trabalho (MADDEN, 1981) tem efeitos negativos sobre a comutação; e pessoas iniciando no mercado de trabalho comutam mais do que a média (ROUWENDAL; RIETVELD, 1994).

Na literatura nacional, destaca-se o trabalho de Pereira e Schwanen (2013), que aborda, para nove regiões metropolitanas brasileiras, entre 1992 e 2009, a evolução do tempo de deslocamento diário dos trabalhadores brasileiros. Entre os principais resultados, os autores verificaram que, em 2009, as regiões metropolitanas de São Paulo (RMSP) e do Rio de Janeiro (RMRJ) apresentavam tempo de deslocamento médio casa-trabalho em torno 
de $30 \%$ superior às demais e trabalhadores de baixa renda comutavam, em média, 20\% a mais do que suas contrapartes mais favorecidas.

Voltando a atenção para o mercado de trabalho, Haddad e Vieira (2015), utilizando dados da Pesquisa Origem-Destino de 2007 para a RMSP e dados do Censo 2010, analisam a relação entre tempo de deslocamento, mobilidade e produtividade do trabalho. Os autores concluem que uma diminuição de aproximadamente $28 \%$ no tempo de viagem acarretaria um aumento de aproximadamente $16 \%$ na produtividade dos trabalhadores na RMSP.

Ainda em nível macroeconômico, destaca-se o trabalho de Vianna e Young (2015), que, a partir de dados do Censo 2010, estimam que a perda econômica em função de problemas de mobilidade urbana equivale a $1,8 \%$ do PIB. Em outras palavras, melhorias na mobilidade urbana podem trazer grandes retornos sociais. Portanto, mostra-se a relevância do tema do ponto de vista do bem-estar social.

\section{Estratégia metodológica}

Nesta seção, são apresentadas a metodologia aplicada - o método GoM -, a base de dados e as variáveis selecionadas.

\section{Grade of Membership}

Para alcançar o objetivo proposto, de criar tipologias da comutação, é utilizado o método Grade of Membership (GoM). Uma vantagem do método é que ele parte dos próprios dados para a captação dos perfis, assim como a heterogeneidade individual também deve ser estimada a partir dos dados (TOLLEY; MANTON, 1992). Logo, não há uma definição predeterminada do que caracteriza cada perfil.

O GoM se baseia na teoria dos conjuntos difusos (fuzzy sets), na qual é possível que qualquer elemento não pertença totalmente a um único conjunto. ${ }^{2}$ Modelos que consideram os conjuntos como nebulosos lidam de forma mais satisfatória com tipos mais complexos de heterogeneidade nos dados (TOLLEY; MANTON, 1992).

O primeiro passo na implementação do método GoM é a identificação dos chamados perfis extremos, que consistem em dois ou mais perfis bem definidos dentre todos os elementos do conjunto. A estes perfis extremos ou perfis de referência, são relacionados os demais elementos por graus de pertencimento. Esse método requer que o pesquisador defina previamente o número de perfis extremos. Impõe-se, então, a questão de quantos perfis devem ser escolhidos. Manton, Tolley e Woodbury (1994) afirmam que seis classes são suficientes para descrever os dados, sendo, em última instância, o número final de perfis extremos dependente em grande parte dos objetivos de análise do pesquisador (MELO, 2006). Portanto, para a consecução deste trabalho, algumas especificações foram testadas a fim de se encontrar a mais adequada.

\footnotetext{
$\overline{2}$ Para mais detalhes, ver Woodbury, Manton e Tolley (1994).
} 
Seguindo Manton, Tolley e Woodbury (1994), ${ }^{3}$ para cada observação é determinado um escore de grau de pertencimento $\left(g_{i k}\right)$, indicando o grau de pertencimento de determinado elemento $i$ a dado perfil $k$, o que pode assumir valores entre 0 e 1 . Se o escore assumir valor 1 , o indivíduo é caracterizado como pertencente completamente a determinado perfil, se assumir valor 0 , o indivíduo não pertence ao perfil e, se tiver entre 0 e 1, o indivíduo tem características de mais de um perfil de referência. 0 escore de grau de pertencimento deve respeitar às seguintes restrições:

$g_{i k} \geq 0$ para todo $i$ e $k$, onde $i=1, \ldots, I$ e $k=1, \ldots K$,

$\sum_{k=1}^{K} g_{i k}=1$ para todo $i$.

Para determinar quais atributos são relacionados a cada perfil extremo, é necessário um termo $\lambda_{k j l}$ que expresse a probabilidade da resposta $l$ dada pelo indivíduo com o k-ésimo perfil extremo para a j-ésima questão ou medida. Este termo deve respeitar às seguintes restrições:

$\lambda_{k j l} \geq 0$ para cada $k, j$, e $l$.

$\sum_{l=1}^{L j} \lambda_{k j l}=1$ para cada $k$ e $j$.

O software utilizado para gerar as estimativas foi o Stata 14.

\section{Dados}

A Pesquisa Nacional por Amostra de Domicílios (PNAD) é um levantamento anual que obtém informações demográficas e socioeconômicas da população brasileira, bem como características domiciliares. Como afirmado anteriormente, são utilizados dados das PNADs de 2009 e 2014. A escolha deste período foi baseada nas informações disponíveis. Em 2009, pela primeira vez foi investigada a posse de veículo motor para uso próprio e, em 2014, no momento de confecção deste estudo, era o último ano com dados disponíveis. Em 2009, a amostra original contava com 399.387 observações, enquanto em 2014 esse número é de 362.627. A informação sobre a posse de veículos automotores refere-se à presença de veículo para uso pessoal no domicílio, não havendo informação sobre quem utiliza o veículo e se é utilizado para deslocamento para trabalho ou escola, etc.

Para a consecução dos objetivos propostos neste ensaio, devido às peculiaridades das atividades exercidas por crianças, adolescentes e idosos, restringiu-se a amostra para pessoas com idade entre 21 e 65 anos, pois a intenção é analisar uma amostra de indivíduos em idade de trabalhar. Pessoas que trabalhavam, mas não reportaram quantas horas gastavam por semana em cada trabalho também foram excluídas, assim como aqueles que não reportaram tempo gasto com comutação e no trabalho, os que não informaram ocupação ou que possuem ocupações mal definidas e os indivíduos cuja posição no domicílio não era de responsável, cônjuge ou filho(a).

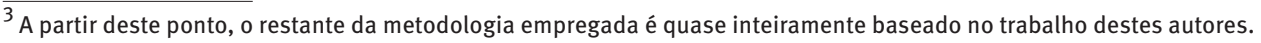


Com relação à cor, são considerados brancos, pretos e pardos. Excluem-se os indígenas e amarelos, por serem pouco representativos.

QUADRO 1

Variáveis categóricas utilizadas para criação das tipologias

\begin{tabular}{|c|c|}
\hline Nome & Descrição \\
\hline Comut & $\begin{array}{l}\text { Variável categórica que define se o trabalhador não gasta nada até o trabalho, se gasta até } 30 \\
\text { minutos, se gasta mais de } 30 \text { minutos até } 1 \text { hora, se gasta mais de } 1 \text { hora até } 2 \text { horas, ou se } \\
\text { gasta mais de } 2 \text { horas. }\end{array}$ \\
\hline Horas_trab & $\begin{array}{l}\text { Variável categórica que define se o indivíduo trabalha até } 35 \text { horas por semana; se trabalha } \\
\text { mais de } 35 \text { até } 40 \text { horas; se trabalha mais de } 40 \text { até } 45 \text { horas; se trabalha mais de } 45 \text { até } 50 \\
\text { horas; ou se trabalha mais de } 50 \text { horas por semana. }\end{array}$ \\
\hline Horas_dom & $\begin{array}{l}\text { Variável categórica que define se o trabalhador nada gasta em afazeres domésticos por } \\
\text { semana; se gasta até cinco horas; se gasta mais de cinco horas até } 10 \text { horas; se gasta mais de } \\
10 \text { horas até } 20 \text { horas; ou se gasta mais de } 20 \text { horas. }\end{array}$ \\
\hline Sexo & Dummy que define se o trabalhador é do sexo masculino ou feminino. \\
\hline Cor & Variável categórica que define se o trabalhador se autodeclara de cor branca, parda ou preta. \\
\hline Idade & $\begin{array}{l}\text { Variável categórica que define se o indivíduo tem entre } 21 \text { e } 25 \text { anos, entre } 26 \text { e } 30 \text { anos, entre } \\
31 \text { e } 40 \text {, entre } 41 \text { e } 50 \text { e entre } 51 \text { e } 65 \text { anos. }\end{array}$ \\
\hline Freq_esc & Dummy que define se o indivíduo frequenta ou não escola ou curso. \\
\hline Educ & $\begin{array}{l}\text { Variável categórica que define se o trabalhador é sem instrução; se possui ensino fundamental } \\
\text { incompleto ou equivalente; se possui fundamental completo ou equivalente; se possui médio } \\
\text { incompleto ou equivalente; se possui médio completo ou equivalente; se possui superior } \\
\text { incompleto ou equivalente; ou se possui superior completo. }\end{array}$ \\
\hline Pos_ocup & $\begin{array}{l}\text { Variável categórica que define se o indivíduo é empregado com carteira de trabalho assinada; } \\
\text { se é militar ou funcionário público estatutário; se é empregado sem carteira de trabalho } \\
\text { assinada; se é trabalhador doméstico; se é conta-própria; ou se é empregador. }\end{array}$ \\
\hline Gru_ocup & $\begin{array}{l}\text { Variável categórica que define se o grupamento ocupacional do trabalhador é de dirigentes } \\
\text { em geral; se é de profissionais das ciências e das artes; se é de técnicos de nível médio; se } \\
\text { é de trabalhadores dos serviços administrativos; se é de trabalhadores dos serviços; se é } \\
\text { de vendedores e prestadores de serviço de comércio; se é de trabalhadores agrícolas; se é } \\
\text { de trabalhadores da produção de bens e serviços e de reparação e manutenção; ou se é de } \\
\text { membros das Forças Armadas. }\end{array}$ \\
\hline Tipo_fam & $\begin{array}{l}\text { Variável categórica que define se o domicílio é composto por casal sem filhos; se é composto } \\
\text { por casal com filhos; se é composto por mãe e filho(s) apenas; ou outros tipos de famílias. }\end{array}$ \\
\hline Renda & $\begin{array}{l}\text { Variável categórica que define se a renda domiciliar per capita é de até } R \$ 400 \text {; se está acima } \\
\text { de } R \$ 400 \text { até } R \$ 650 \text {; acima de } R \$ 650 \text { até } R \$ 950 ; \text { acima de } R \$ 950 \text { até } R \$ 1.600 ; \text { ou acima } \\
\text { de } R \$ 1.600 \text {. }\end{array}$ \\
\hline Auto & $\begin{array}{l}\text { Variável categórica que define se no domicílio não há carro nem motocicleta; se o domicílio } \\
\text { possui carro; se possui motocicleta; ou se possui carro e motocicleta no domicílio para uso } \\
\text { pessoal. }\end{array}$ \\
\hline RM & Variável binária que define se o domicílio está localizado em região metropolitana. \\
\hline
\end{tabular}

Fonte: Elaboração dos autores.

Optou-se por excluir os domicílios com renda familiar muito baixa (renda domiciliar per capita abaixo de $\mathrm{R} \$ 30,00$ mensais) e também os muitos ricos (acima de $\mathrm{R} \$ 100.000$ mensais per capita). A exclusão destes dois grupos extremos deve-se ao fato de que o primeiro não apresenta muitas opções de escolha, enquanto o segundo embasa suas decisões de forma diferenciada. Por fim, como neste trabalho foi tomada a decisão de serem analisados apenas os deslocamentos realizados pelos indivíduos que trabalhavam, a amostra é restrita 
aos ocupados na semana de referência. A amostra final conta com 114.569 observações em 2009 e 109.939 em 2014.

Para a aplicação do método GoM, as variáveis contínuas devem ser categorizadas. Terrell e Scott (1985) argumentam que o número de categorias necessárias para representar uma variável contínua raramente passa de 15. Manton, Tolley e Woodbury (1994) afirmam que, em muitos casos, de cinco a dez categorias são suficientes para representar a informação contida na variável contínua.

As variáveis utilizadas para criação das tipologias são descritas no Quadro 1. As variáveis que definem o tempo comutado, o gênero do trabalhador, a cor declarada, se frequenta atualmente escola, a escolaridade do indivíduo, a composição familiar, a posição do trabalhador no emprego, o grupo ocupacional ao qual pertence, se possui veículo automotor e se reside ou não em área metropolitana são naturalmente categóricas, ou seja, podem ser diretamente utilizadas pela técnica GoM. Já aquelas que definem idade, renda domiciliar per capita, horas trabalhadas semanalmente e o número de horas que o trabalhador gasta semanalmente em atividades domésticas são contínuas, porém foram categorizadas devido às questões explicadas anteriormente. As categorias foram definidas e ordenadas em intervalos baseados em quantis, com os menores valores no primeiro e os maiores no último.

Como pode ser observado no Quadro 1, comutação é entendida como o tempo de deslocamento de casa até o trabalho, ou seja, é apenas a ida para o trabalho.

Para a definição de afazeres domésticos, enquadram-se as tarefas realizadas no domicílio de residência, que não se enquadram na definição de trabalho, quais sejam: arrumar ou limpar toda ou parte da moradia; cozinhar ou preparar alimentos; passar roupa; lavar roupa ou louça; orientar ou dirigir trabalhadores domésticos na execução das tarefas domésticas; cuidar de filhos ou menores moradores; limpar o quintal ou terreno que circunda a residência (IBGE, 2008).

As variáveis sexo, cor e nível educacional, como mencionado, influenciam na inserção do indivíduo no mercado de trabalho (LEME; WAJNMAN, 2000; BARROS et al., 2001; LEONE; BALTAR, 2006; MADALOZZO, 2010; HAUSSMANN; GOLGHER, 2016). Idade é importante, pois parte da literatura atesta que jovens comutam mais e utilizam mais transporte público (BOJE et al., 2010), mas o padrão observado por Wyly (1998) é de um U invertido, ou seja, tempo comutado cresce com a idade, porém passa a decrescer a partir de determinado ponto. Analisar se o trabalhador estuda é importante, pois o fato de ter que comutar para dois diferentes pontos pode alterar as escolhas de onde trabalhar e estudar.

Variáveis relacionadas à posição e ao grupo ocupacional são importantes porque, como afirma Shearmur (2006), existem evidências de que diferentes tipos de emprego localizam-se em diferentes partes do espaço. Além disso, a posição na ocupação influencia rendimentos, que influenciam tipo de transporte a ser escolhido.

Estudos diversos mostram a relação entre a estrutura urbana, modo de transporte e distâncias comutadas (CERVERO; DUNCAN, 2003; GREENWALD; BOARNET, 2001). Por 
esse motivo, é incluída na análise a variável que define se o domicílio se encontra em área metropolitana.

\section{Resultados}

Nesta seção, primeiramente são apresentadas as estatísticas descritivas, a fim de conhecer melhor os dados. Posteriormente, são interpretados os resultados das estimativas via o método GoM.

\section{Estatísticas descritivas}

A região de residência tem efeitos sobre o tempo gasto com comutação diária. Como pode ser visto no Gráfico 1, em regiões metropolitanas, não apenas o percentual de indivíduos que gastam mais de uma hora no deslocamento diário é mais elevado do que em regiões não metropolitanas, como houve crescimento considerável do percentual de commuters de longas durações.

\section{GRÁFICO 1}

Percentual de indivíduos que gastam mais de 1 hora no deslocamento até o trabalho Brasil - 2009-2014

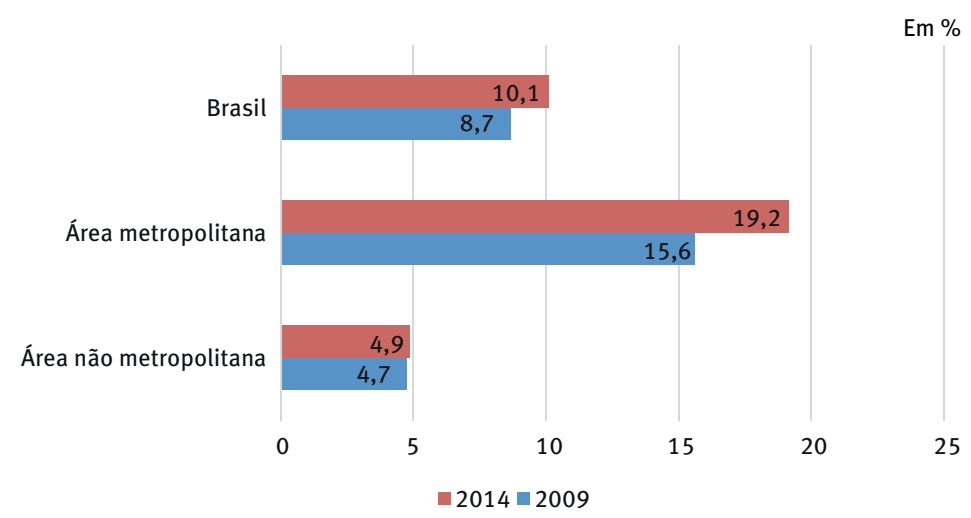

Fonte: IBGE. Pesquisa Nacional por Amostra de Domicílios (PNAD) 2009 e 2014. Elaboração dos autores.

Na Tabela 1 são apresentadas estatísticas descritivas para diversos grupos por diferentes tempos comutados. Comparando primeiramente por sexo, observa-se como o percentual dos que nada comutam é bem maior entre as mulheres em relação aos homens (14,06\% contra $8,43 \%)$. Já para aqueles que comutam mais de duas horas, entre os homens o percentual é mais elevado (2,18\% contra $1,32 \%$ ). A literatura sobre o tema, em geral, aponta que homens comutam, em média, mais do que mulheres (WYLY, 1998; CLARK; HUANG; WITHERS, 2003; SHEARMUR, 2006). Entretanto Van Ommeren e Puigarnau (2011) não encontraram diferenças significativas das distâncias comutadas diariamente por homens e mulheres.

Com relação à idade, percebe-se que, quanto mais velhos os trabalhadores, maiores os percentuais daqueles que nada comutam. No que tange a cor do trabalhador, observa-se 
que os pardos e pretos sofrem mais com a comutação do que os brancos, principalmente os primeiros. Entre os grupos comparados na Tabela 1, os pretos são os que apresentam maior percentual de indivíduos que demoram mais de duas horas para chegarem ao trabalho diariamente.

A frequência à escola leva a algumas diferenças em termos de comutação diária. Entre os que frequentam, o percentual dos que nada comutam é inferior se comparado àqueles que não estudam. Uma possível explicação é que, já que gastam tempo e dinheiro comutando para a escola, é possível que tenham ocupações próximas à escola ou no caminho entre trabalho e residência, de forma a otimizar o tempo despendido. Ao mesmo tempo, é menos provável que comutem distâncias muito elevadas entre casa e trabalho, porque precisam também comutar para o local de estudo.

Quando se comparam os trabalhadores segundo os níveis de instrução, diferenças importantes emergem. Primeiramente, percebe-se que os analfabetos ou com ensino fundamental incompleto apresentam os mais elevados percentuais dos que nada comutam $(12,99 \%)$ e também a maior proporção dos que comutam mais de duas horas $(2,03 \%)$. Ademais, à medida que a escolaridade aumenta, decresce o percentual dos que nada comutam (de $12,99 \%$ para $7,71 \%$ ), bem como o de trabalhadores que comutam mais de duas horas (de $2,03 \%$ para $1,46 \%$ ).

Com relação à renda domiciliar per capita, nenhum padrão claro pode ser observado, ou seja, se são pobres ou ricos que comutam mais. De acordo com Brueckner (2011), a fonte desta ambiguidade é a presença de duas forças conflitantes: o desejo, por parte dos mais ricos, de alugar ou comprar residências maiores os leva a morar nos subúrbios, enquanto o desejo de gastar menor tempo comutando os conduz mais próximo aos centros.

A posição na ocupação é a variável que gera maiores diferenças (Tabela 1). Primeiramente, observa-se como é elevado o percentual dos que nada comutam entre trabalhadores por conta-própria. Para efeito de comparação, a proporção de indivíduos que nada comutam entre os conta-próprias (34,7\%) é aproximadamente 15 pontos percentuais superior à de empregadores (19,7\%), o grupo ocupacional com o segundo maior percentual. Em contrapartida, os trabalhadores com carteira de trabalho assinada apresentam a maior proporção dos que comutam mais de 30 minutos até uma hora $(26,04 \%)$, enquanto os trabalhadores domésticos registram as maiores proporções entre aqueles que comutam mais de uma hora até duas horas (10,71\%) e os que comutam mais de duas horas $(2,33 \%)$. Voltando a atenção para os empregadores, estes detêm a menor proporção entre todos os grupos para comutação de mais de uma e mais de duas horas $(2,57 \%$ e $0,99 \%$, respectivamente). Militares e funcionários públicos possuem a menor proporção daqueles que nada comutam (3,32\%) e a maior entre os que comutam até 30 minutos $(71,47 \%)$.

Por fim, ainda com relação à Tabela 1, observa-se que a posse de carro ou motocicleta está atrelada a menores tempos gastos comutando. Isso pode ser consequência do fato de a posse do veículo automotor tornar mais rápida a comutação, além de influenciar na escolha de onde residir. 
TABELA 1

Distribuição dos trabalhadores, por tempo diário gasto de casa até o trabalho, segundo variáveis demográficas e socioeconômicas

Brasil - 2009/2014

Em porcentagem

\begin{tabular}{|c|c|c|c|c|c|}
\hline \multirow[b]{2}{*}{ Variáveis demográficas e socioeconômicas } & \multicolumn{5}{|c|}{ Tempo gasto de casa até o trabalho } \\
\hline & Nada & $\begin{array}{l}\text { Até } 30 \\
\text { min. }\end{array}$ & $\begin{array}{l}31-60 \\
\text { min. }\end{array}$ & $\begin{array}{c}61-120 \\
\min .\end{array}$ & $\begin{array}{l}\text { Mais de } \\
2 \text { horas }\end{array}$ \\
\hline Homens & 8,4 & 59,6 & 21,8 & 8,0 & 2,2 \\
\hline Mulheres & 14,1 & 58,4 & 19,0 & 7,2 & 1,3 \\
\hline Idade entre 21 e 30 anos & 7,1 & 61,3 & 22,0 & 8,0 & 1,6 \\
\hline Idade entre 31 e 40 anos & 9,9 & 59,9 & 20,7 & 7,8 & 1,8 \\
\hline Idade entre 41 e 50 anos & 12,4 & 58,0 & 20,4 & 7,4 & 1,9 \\
\hline Idade acima de 50 anos & 16,4 & 55,8 & 18,6 & 7,2 & 2,1 \\
\hline Brancos & 11,1 & 61,0 & 19,5 & 6,8 & 1,6 \\
\hline Pretos & 9,0 & 54,1 & 24,1 & 10,4 & 2,4 \\
\hline Pardos & 11,1 & 57,8 & 21,2 & 8,1 & 1,9 \\
\hline Não frequenta escola & 11,2 & 58,8 & 20,5 & 7,6 & 1,8 \\
\hline Frequenta escola & 7,3 & 62,1 & 21,4 & 8,0 & 1,3 \\
\hline Instrução até ensino primário incompleto & 13,0 & 58,2 & 19,6 & 7,2 & 2,0 \\
\hline Instrução até ensino médio incompleto & 12,1 & 58,1 & 20,4 & 7,6 & 1,9 \\
\hline Instrução até superior incompleto & 10,3 & 58,4 & 21,5 & 8,2 & 1,7 \\
\hline Instrução superior completo ou mais & 7,7 & 63,3 & 20,5 & 7,1 & 1,5 \\
\hline Renda per capita até $\mathrm{R} \$ 250,00$ & 13,0 & 59,6 & 18,7 & 6,8 & 1,9 \\
\hline Renda per capita acima $\mathrm{R} \$ 250,00$ e até $\mathrm{R} \$ 650,00$ & 10,9 & 58,2 & 21,2 & 8,0 & 1,8 \\
\hline Renda per capita acima de $\mathrm{R} \$ 650,00$ até $\mathrm{R} \$ 1.200,00$ & 10,6 & 58,3 & 21,4 & 8,0 & 1,7 \\
\hline Renda per capita acima de $\mathrm{R} \$ 1.200,00$ até $\mathrm{R} \$ 2.500,00$ & 11,1 & 60,0 & 19,6 & 7,4 & 1,9 \\
\hline Renda per capita acima de $\mathrm{R} \$ 2.500,00$ & 10,5 & 61,6 & 19,8 & 6,4 & 1,8 \\
\hline Casal sem filhos & 11,5 & 59,7 & 19,8 & 7,3 & 1,8 \\
\hline Casal com filhos & 10,6 & 59,5 & 20,5 & 7,5 & 1,9 \\
\hline Mãe com filhos & 10,4 & 57,1 & 22,4 & 8,4 & 1,7 \\
\hline Pessoa de referência no domicílio & 11,3 & 59,2 & 20,0 & 7,5 & 2,0 \\
\hline Cônjuge da pessoa de referência & 13,1 & 59,0 & 19,3 & 7,2 & 1,6 \\
\hline Filho(a) & 6,8 & 58,8 & 24,1 & 8,6 & 1,7 \\
\hline Empregados com carteira de trabalho assinada & 3,7 & 57,9 & 26,0 & 10,3 & 2,0 \\
\hline Militares e funcionários públicos estatutários & 3,3 & 71,5 & 18,0 & 5,8 & 1,4 \\
\hline Empregados sem carteira de trabalho assinada & 5,9 & 68,8 & 17,9 & 5,8 & 1,6 \\
\hline Trabalhadores domésticos & 4,1 & 59,6 & 23,3 & 10,7 & 2,3 \\
\hline Conta própria & 34,7 & 47,4 & 12,8 & 3,5 & 1,6 \\
\hline Empregadores & 19,7 & 67,2 & 9,6 & 2,6 & 1,0 \\
\hline Não possui carro nem moto & 10,6 & 53,2 & 24,2 & 9,9 & 2,1 \\
\hline Possui carro & 11,4 & 58,9 & 20,5 & 7,4 & 1,8 \\
\hline Possui moto & 10,3 & 68,7 & 15,2 & 4,6 & 1,2 \\
\hline Possui carro e moto & 11,1 & 70,1 & 13,8 & 3,9 & 1,1 \\
\hline Reside em região metropolitana & 10,4 & 42,5 & 29,7 & 14,5 & 3,0 \\
\hline
\end{tabular}

Fonte: IBGE. Pesquisa Nacional por Amostra de Domicílios (PNAD) 2009 e 2014. Elaboração dos autores. 


\section{Estimativas via o método GoM}

As descrições apresentadas na Tabela 1 mostraram-se heterogêneas, com alguns padrões bem definidos e outros mais diversos, de difícil interpretação. Os perfis gerados pelo método GoM podem ajudar a melhor entender as características atreladas ao tempo gasto com deslocamento diário.

Diversas construções distintas foram testadas a fim de se encontrar o modelo mais adequado, em termos de número de perfis e escores de pertencimento. Seguindo o procedimento utilizado por Guedes et al. (2010), foi calculada a estatística AIC (Akaike Criterion Information) e os resultados são apresentados na Tabela 2.

TABELA 2

Valores do Akaike Criterion Information (AIC)

\begin{tabular}{cccc}
\hline $\begin{array}{c}\text { Número de perfis } \\
\text { extremos }\end{array}$ & $\begin{array}{c}\text { Número de parâmetros } \\
(\mathrm{p})\end{array}$ & Ln (L) (1) & AIC (2) \\
\hline 2 & 449.202 & -8.344 .965 & 17.588 .334 \\
3 & 673.803 & -7.771 .602 & 16.890 .810 \\
4 & 898.404 & -7.430 .434 & 16.657 .676 \\
5 & 1.123 .005 & -7.200 .386 & 16.646 .782 \\
\hline
\end{tabular}

Fonte: IBGE. Pesquisa Nacional por Amostra de Domicílios (PNAD) 2009 e 2014. Elaboração dos autores.

(1) $L=$ função de verossimilhança

(2) AIC foi calculado a partir da fórmula AIC $=2 p-2 \ln (L)$.

0 número de perfis extremos que minimizam o AIC é 5 . Entretanto, a especificação com quatro perfis se mostrou a mais adequada para o objetivo principal proposto neste trabalho, que é criar perfis com características específicas com relação ao tempo comutado. Quantidade menor de perfis gerava uma agregação excessiva de características, escondendo diferenças existentes, enquanto um maior número de perfis, entre estes a escolha de cinco perfis extremos, tendia a homogeneizar os resultados.

Os perfis são descritos pela análise das probabilidades estimadas (lambdas), para cada um dos quatro perfis, considerando cada resposta a cada variável, tendo como referência a distribuição da frequência marginal das respostas. Para a identificação dos perfis extremos, considerou-se uma linha de corte de 1,2 para a relação entre as probabilidades e a frequência. Tal escolha é feita com base na literatura que utiliza tal metodologia (SAWYER; LEITE; ALEXANDRINO, 2002; MELO, 2006; CERQUEIRA; SAWYER, 2007). Explicando com mais detalhes, sempre que o resultado da divisão do lambda pela frequência da mesma resposta à variável for superior a 1,2, entende-se que o perfil é caracterizado por apresentar uma probabilidade relativamente maior daquela resposta à variável, quando comparada com todas as observações da amostra.

Os resultados encontram-se na Tabela 1 no Apêndice. A última coluna da tabela (“Lambdas / freq"), que é subdividida em quatro colunas menores, correspondendo a cada um dos perfis, possui células destacadas indicando características que apresentam valor de pertencimento superior ao ponto de corte escolhido. Com base nestas, foram caracterizados e denominados os perfis extremos. Ressalta-se que a identificação dos 
perfis resulta de um balanço de probabilidades quanto às respostas a cada categoria de cada variável independentemente, no qual o perfil extremo agrega as características mais prováveis, relativamente, de pertencerem a ele (MELO, 2006).

0 Quadro 2 sumariza os resultados encontrados. Os nomes sintéticos dados aos perfis são de acordo com as características que mais se destacaram, sem necessariamente serem relacionados ao quanto o indivíduo comuta.

QUADRO 2

Caracterização dos perfis extremos com base nas probabilidades de respostas às variáveis

\begin{tabular}{|c|c|c|c|c|}
\hline \multirow[b]{2}{*}{ Variáveis } & \multicolumn{4}{|c|}{ Perfis } \\
\hline & $\begin{array}{c}\text { Posição } \\
\text { socioeconômica } \\
\text { elevada }\end{array}$ & $\begin{array}{l}\text { Mulheres em } \\
\text { baixa posição } \\
\text { socioeconômica }\end{array}$ & $\begin{array}{l}\text { Homens não } \\
\text { metropolitanos }\end{array}$ & $\begin{array}{c}\text { Homens } \\
\text { metropolitanos }\end{array}$ \\
\hline Commuting & Não discrimina & Nada & Até 30 minutos & $\begin{array}{l}\text { Acima de } 30 \text { minutos } \\
\text { até uma hora; mais } \\
\text { de uma hora até } \\
\text { duas horas; mais de } \\
\text { duas horas }\end{array}$ \\
\hline Sexo & Feminino & Feminino & Masculino & Masculino \\
\hline Cor & Branca & Preta & Não discrimina & Preta \\
\hline Idade & Não discrimina & Não discrimina & Não discrimina & Não discrimina \\
\hline $\begin{array}{l}\text { Frequenta } \\
\text { escola? }\end{array}$ & Sim & Não discrimina & Não discrimina & Não discrimina \\
\hline $\begin{array}{l}\text { Nível } \\
\text { educacional }\end{array}$ & $\begin{array}{l}\text { Superior incompleto; } \\
\text { superior completo }\end{array}$ & $\begin{array}{l}\text { Fundamental } \\
\text { incompleto; } \\
\text { fundamental completo; } \\
\text { médio incompleto; } \\
\text { médio completo }\end{array}$ & $\begin{array}{l}\text { Sem instrução; } \\
\text { fundamental incompleto; } \\
\text { fundamental completo; } \\
\text { médio incompleto }\end{array}$ & $\begin{array}{l}\text { Fundamental } \\
\text { completo; médio } \\
\text { incompleto; médio } \\
\text { completo }\end{array}$ \\
\hline Tipo de família & Casal sem filhos & Mãe e filhos apenas & Não discrimina & Não discrimina \\
\hline $\begin{array}{l}\text { Posição na } \\
\text { ocupação }\end{array}$ & $\begin{array}{l}\text { Militares e funcionários } \\
\text { públicos estatutários; } \\
\text { empregadores }\end{array}$ & $\begin{array}{l}\text { Trabalhadores } \\
\text { domésticos }\end{array}$ & $\begin{array}{l}\text { Empregados sem } \\
\text { carteira de trabalho } \\
\text { assinada; conta própria }\end{array}$ & $\begin{array}{l}\text { Empregados com } \\
\text { carteira de trabalho } \\
\text { assinada }\end{array}$ \\
\hline $\begin{array}{l}\text { Grupos } \\
\text { ocupacionais }\end{array}$ & $\begin{array}{l}\text { Dirigentes em geral; } \\
\text { profissionais das } \\
\text { ciências e das artes; } \\
\text { técnicos de nível médio; } \\
\text { trabalhadores de } \\
\text { serviços administrativos; } \\
\text { membros das Forças } \\
\text { Armadas e auxiliares }\end{array}$ & $\begin{array}{l}\text { Trabalhadores dos } \\
\text { serviços; vendedores e } \\
\text { prestadores de serviço } \\
\text { do comércio }\end{array}$ & $\begin{array}{l}\text { Trabalhadores agrícolas; } \\
\text { trabalhadores da } \\
\text { produção de bens e } \\
\text { serviços e de reparação } \\
\text { e manutenção }\end{array}$ & $\begin{array}{l}\text { Trabalhadores } \\
\text { da produção de } \\
\text { bens e serviços } \\
\text { e de reparação } \\
\text { e manutenção; } \\
\text { membros das Forças } \\
\text { Armadas e auxiliares }\end{array}$ \\
\hline Renda familiar & $\begin{array}{l}\text { Acima de } \mathrm{R} \$ 950 \text { até } \\
\mathrm{R} \$ 1.600 ; \text { acima de } \\
\mathrm{R} \$ 1.600\end{array}$ & $\begin{array}{l}\text { Até } R \$ 400 ; \text { acima de } \\
\mathrm{R} \$ 400 \text { até } \mathrm{R} \$ 650 ; \\
\text { acima de } \mathrm{R} \$ 650 \text { até } \\
\mathrm{R} \$ 950\end{array}$ & Até $\mathrm{R} \$ 400$ & $\begin{array}{l}\text { Acima de } R \$ 400 \text { até } \\
R \$ 650\end{array}$ \\
\hline $\begin{array}{l}\text { Horas } \\
\text { trabalhadas } \\
\text { semanalmente }\end{array}$ & $\begin{array}{l}\text { Acima de } 35 \text { até } 40 \\
\text { horas }\end{array}$ & Até 35 horas & $\begin{array}{l}\text { Acima de } 40 \text { até } 45 \\
\text { horas; acima de } 50 \\
\text { horas }\end{array}$ & $\begin{array}{l}\text { Acima de } 40 \text { até } 45 \\
\text { horas; acima de } 45 \\
\text { até } 50 \text { horas }\end{array}$ \\
\hline $\begin{array}{l}\text { Horas } \\
\text { dedicadas } \\
\text { aos afazeres } \\
\text { domésticos } \\
\text { semanalmente }\end{array}$ & $\begin{array}{l}\text { Acima de } 0 \text { até } 5 \text { horas; } \\
\text { acima de } 5 \text { até } 10 \text { horas }\end{array}$ & $\begin{array}{l}\text { Acima de } 10 \text { e abaixo } \\
\text { de } 20 \text { horas; } 20 \text { horas } \\
\text { ou mais }\end{array}$ & $\begin{array}{l}\text { Nada; acima de } 0 \text { até } 5 \\
\text { horas }\end{array}$ & $\begin{array}{l}\text { Nada; acima de } 0 \text { até } \\
5 \text { horas }\end{array}$ \\
\hline $\begin{array}{l}\text { Possui } \\
\text { automóvel? }\end{array}$ & $\begin{array}{l}\text { Tem carro; tem carro e } \\
\text { motocicleta }\end{array}$ & Não possui & $\begin{array}{l}\text { Tem motocicleta; tem } \\
\text { carro e motocicleta }\end{array}$ & Não possui \\
\hline $\begin{array}{l}\text { Vive em região } \\
\text { metropolitana? }\end{array}$ & Não discrimina & Não discrimina & Não & Sim \\
\hline
\end{tabular}

Fonte: IBGE. Pesquisa Nacional por Amostra de Domicílios (PNAD) 2009 e 2014. Elaboração dos autores. 
Primeiramente, destaca-se que nenhum perfil extremo apresentou caracterização por faixas de idade. Analisando os escores de pertencimento, o primeiro perfil extremo foi determinado como "posição socioeconômica elevada" e não apresenta característica predominante com relação ao tempo comutado, abrangendo, com maiores probabilidades, mulheres, branco(a)s, que frequentam escola ou curso, que possuem superior incompleto ou escolaridade acima, casado(a)s sem filhos, militares, funcionários públicos e empregadores, dirigentes em geral, profissionais das ciências e das artes, técnicos de nível médio, trabalhadores de serviços administrativos, membros das Forças Armadas e auxiliares, renda domiciliar per capita acima de $\mathrm{R} \$ 950,00$ mensais, que trabalham entre 35 e 40 horas por semana, realizam até dez horas de serviços domésticos semanalmente, possuem carro, ou carro e motocicleta. Por fim, o perfil não discrimina por área censitária de residência.

O segundo perfil extremo é denominado "mulheres em baixa posição socioeconômica”, que apresenta predomínio de trabalhadores que nada comutam. Além disso, também registra predominância de mulheres, assim como indivíduos que se autodeclaram de cor preta, possuem escolaridade entre fundamental incompleto e médio completo, vivem em domicílios com mãe e filhos apenas, trabalhadores domésticos, trabalhadores dos serviços, vendedores e prestadores de serviço do comércio, renda domiciliar per capita de até R\$ 950,00 mensais, trabalham até 35 horas semanais, realizam acima de dez horas semanais de atividades domésticas e não possuem veículo automotor. Por fim, assim como o perfil extremo indicado anteriormente, este também não traz discriminação por área censitária.

O terceiro perfil extremo é denominado "homens não metropolitanos", apresentando proporção elevada de indivíduos que comutam até 30 minutos, além de predominância de homens, com até o médio incompleto, empregados sem carteira de trabalho assinada, trabalhadores por conta própria, trabalhadores agrícolas e trabalhadores da produção de bens e serviços e de reparação e manutenção, renda domiciliar per capita mensal de até $\mathrm{R} \$ 400,00$, que alocam mais de 40 horas semanais no trabalho, não realizam afazeres domésticos ou gastam até cinco horas por semana nesta atividade, possuem motocicleta, ou carro e motocicleta, e residem em regiões não metropolitanas. Trata-se do único perfil extremo que não discrimina por cor, além de não discriminar por tipo de família.

Por fim, o quarto perfil extremo é denominado "homens metropolitanos", com predomínio de trabalhadores que gastam mais de 30 minutos por dia no trajeto casa-trabalho. Além disso, apresenta predomínio de homens, pretos, com nível de instrução entre fundamental completo e médio completo, empregados com carteira de trabalho assinada, trabalhadores da produção de bens e serviços e de reparação e manutenção, membros das Forças Armadas e auxiliares, renda domiciliar entre $R \$ 400$ e $R \$ 650,00$. Alocam mais de 40 horas até 49 horas semanais no trabalho, nada realizam de afazeres domésticos ou até cinco horas por semana, não possuem automóveis e residem em área metropolitana. Finalmente, assim como no perfil "homens não metropolitanos", este também não discrimina por tipo de família. Na Tabela 3 são apresentados os percentuais de trabalhadores que apresentaram 
escore pertencimento integral $\left(g_{i k}=1\right)$ a qualquer um dos quatro perfis extremos. Ao todo, apenas $2,39 \%$ dos trabalhadores pertencem integralmente a algum perfil extremo.

TABELA 3

Percentual de trabalhadores pertencentes a perfis extremos Brasil - 2009/2014

\begin{tabular}{|c|c|c|c|c|c|c|c|}
\hline$g_{k}$ & Perfil & Homens & Mulheres & Brancos & Pardos & Pretos & Total \\
\hline$g_{1}=1$ & Posição socioeconômica elevada & 0,1 & 1,5 & 1,4 & 0,0 & 0,0 & 0,7 \\
\hline$g_{2}=1$ & $\begin{array}{l}\text { Mulheres em baixa posição } \\
\text { socioeconômica }\end{array}$ & 0,0 & 2,8 & 0,5 & 1,9 & 2,3 & 1,2 \\
\hline$g_{3}=1$ & Homens não metropolitanos & 0,7 & 0,0 & 0,2 & 0,6 & 0,4 & 0,4 \\
\hline$g_{4}=1$ & Homens metropolitanos & 0,1 & 0,0 & 0,0 & 0,1 & 0,2 & 0,1 \\
\hline Total & & 0,9 & 4,3 & 2,1 & 2,6 & 2,8 & 2,4 \\
\hline
\end{tabular}

Fonte: IBGE. Pesquisa Nacional por Amostra de Domicílios (PNAD) 2009 e 2014. Elaboração dos autores.

Porém, como em Seplaki, Smith e Singer (2004) e adaptando a classificação de Melo (2006), o trabalhador é caracterizado por pertencer a algum perfil puro ${ }^{4}$ ou misto, de acordo com o definido no Quadro 3. Os mesmos nomes dados aos perfis extremos são utilizados nos perfis puros.

QUADRO 3

Classificação dos perfis

\footnotetext{
pertencimento $g$ aos perfis extremos $m, n, o, p$ :

a) $g_{\text {im }} \geq 0,9$; ou

b) $0,75<g_{\text {im }}<0,9$, desde que $g_{\text {in }}<0,1$ e $g_{\text {io }}<0,1$ e $g_{\text {ip }}<0,1$
}

1) $O$ indivíduo $i$ é considerado como pertencente ao perfil puro $m$ quando tiver os seguintes graus de

2) 0 indivíduo i é considerado como pertencente ao perfil misto de $m$ com $n$ se os graus de pertencimento aos perfis $m$ e $n$ forem:

a) $g_{i m}+g_{\text {in }}>0,75$ e $g_{i m}>0,1$ e $g_{\text {in }}>0,1$ e $g_{\text {io }} \leq 0,1$ e $g_{\text {ip }} \leq 0,1$.

3) O estado misto sem predomínio (ou amorfo) ou com predomínio, porém com mais de dois perfis, ocorre quando nenhuma das condições 1 ou 2 ocorrerem.

Fonte: Elaboração dos autores, com base em Melo (2006).

Na Tabela 4, são apresentados os percentuais de indivíduos pertencentes a perfis puros, por gênero e cor, e também pertencentes aos perfis mistos. Observa-se que, entre as mulheres, a preponderância em perfis puros é inferior à dos homens (79,7\% contra 85,5\%). A maior parcela de mulheres está no perfil "posição socioeconômica elevada" (54,5\%) e a de homens no perfil puro "homens não metropolitanos” (47,5\%). Com relação à análise por cor, os trabalhadores são mais distribuídos entre os perfis puros. Para os brancos, $80,6 \%$ estão em algum perfil puro, tendo o perfil "mulher em baixa posição socioeconômica” a maior proporção (28,8\%). Entre os pretos, o perfil com maior proporção é "mulheres em baixa posição socioeconômica", sendo que $85,6 \%$ dos trabalhadores que se autodeclaram pretos pertencem a algum perfil puro. Por fim, $85,2 \%$ dos pardos pertencem a algum perfil puro, apresentando maior representatividade o de "homens não metropolitanos".

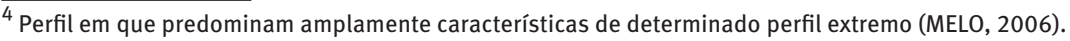


TABELA 4

Distribuição dos trabalhadores, segundo perfis puros e mistos

Brasil - 2009/2015

Fonte: IBGE. Pesquisa Nacional por Amostra de Domicílios (PNAD) 2009 e 2014. Elaboração dos autores.

No que tange os perfis mistos, a interseção entre os grupos se mostra interessante. Criaram-se perfis basicamente femininos (interseção dos perfis puros 1 e 2), não metropolitanos em baixa e elevada posição socioeconômica, metropolitanos em geral (interseção dos perfis puros 1 e 4), assim como um perfil masculino discriminando por posição socioeconômica (interseção dos perfis puros 3 e 4).

0 perfil amorfo mostra pouca representação em todos os grupos considerados. Além disso, utilizando apenas quatro perfis puros, foi possível caracterizar mais de $80 \%$ da amostra, apontando a eficácia do método proposto. Como já esperado, perfis caracterizados por presença de indivíduos considerados em baixa posição socioeconômica são caracterizados por presença elevada de pretos e baixa de brancos, enquanto em perfis com posição socioeconômica elevada, o oposto é verificado.

Como pode ser observado no Gráfico 2, todos os perfis, com exceção do perfil misto "metropolitanos em baixa posição socioeconômica", apresentam como categoria de 
comutação predominante os trabalhadores que comutam até 30 minutos. No perfil citado, a categoria com maior proporção é a daqueles que comutam mais de 30 minutos até uma hora. É interessante notar que, nos perfis metropolitanos, a média de deslocamento é bem mais elevada do que no restante dos perfis. Outro dado interessante é com relação aos perfis de baixa posição socioeconômica, que são caracterizados por percentuais elevados tanto dos que nada comutam quanto dos que comutam muito. Como destacado anteriormente, no geral, os indivíduos já privados em outras características importantes, como renda, também, em média, são privados de tempo.

Novamente, destacam-se as diferenças entre homens e mulheres. Comparando as mulheres e os homens em baixa posição socioeconômica, observa-se que, enquanto entre as mulheres, aproximadamente, $18 \%$ nada comutam, ou seja, realizam as atividades na própria residência, entre os homens esse percentual não chega a 7\%. Em compensação, no perfil masculino ("homens metropolitanos"), cerca de $47 \%$ comutam mais de 30 minutos até 2 horas, enquanto no feminino esse percentual é de apenas $26 \%$. Se compararmos os homens metropolitanos com os metropolitanos em geral, em menor magnitude, as mesmas diferenças emergem.

\section{GRÁFICO 2}

Distribuição dos trabalhadores, por tempo comutado, segundo perfis Brasil - 2009/2014

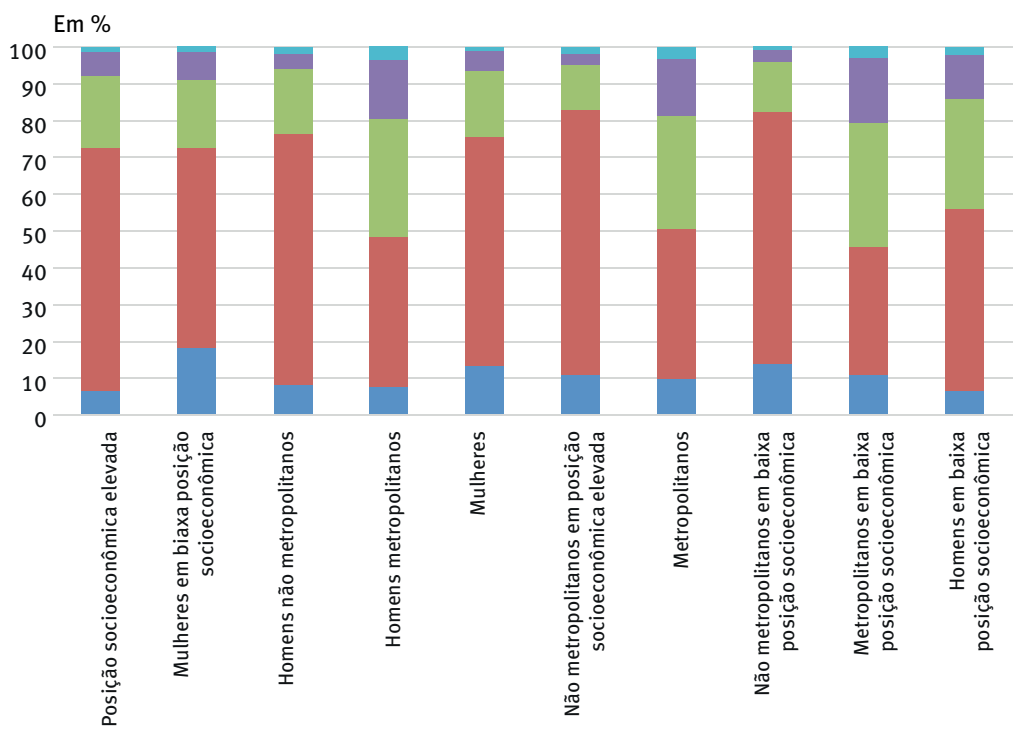

Nada $\square$ Até 30 minutos $\square$ Mais de 30 minutos até 1 hora $\square$ Mais de 1 hora até 2 horas $\square$ Mais de 2 horas Fonte: IBGE. Pesquisa Nacional por Amostra de Domicílios (PNAD) 2009 e 2014. Elaboração dos autores.

Entretanto, a posição socioeconômica importa, assim como defendem White (1986) e Madden (1981). Se compararmos o primeiro perfil puro, que apresenta predominância feminina, com o segundo perfil e com o perfil misto “mulheres”, a proporção das que nada comutam no primeiro é menor em comparação aos outros dois. Porém, em termos de longa comutação, o percentual em perfis femininos ainda é inferior ao observado nos perfis masculinos. 
Por fim, especificamente para longos trajetos (mais de duas horas na ida), todos os perfis metropolitanos são compostos por mais de 3,1\% dos trabalhadores. Já nos perfis não metropolitanos, o máximo observado para a mesma característica é de 1,8\% ("não metropolitanos em posição socioeconômica elevada").

\section{Considerações finais}

O presente estudo investigou padrões demográficos, regionais e socioeconômicos de trabalhadores urbanos no Brasil, com destaque para o tempo de comutação diário destes indivíduos. Dados para todas as Unidades Federativas brasileiras foram utilizados, considerando-se as PNADs 2009 e 2014.

Em função da heterogeneidade característica do mercado de trabalho brasileiro, a estratégia de análise empregada consistiu em desenvolver uma tipologia individual que torna possível, em um segundo momento, realizar análises por tempo comutado. Para a criação da tipologia, empregou-se o método Grade of Membership (GoM), que é indicado para tratar realidades heterogêneas, pois evita a dicotomia dos procedimentos classificatórios padrões, em que determinado elemento deve pertencer ou não integralmente a determinado conjunto. 0 método possibilita uma distribuição mais graduada dos elementos entre as categorias identificadas, lidando melhor com a heterogeneidade (MELO, 2006). Com a criação da tipologia, o objetivo foi facilitar a compreensão do fenômeno comutação.

Foram identificados quatro perfis puros: "posição socioeconômica elevada", "mulheres em baixa posição socioeconômica", "homens não metropolitanos" e "homens metropolitanos". Além disso, sete perfis mistos foram definidos, combinando, em diferentes graus, características dos perfis puros. As características prováveis do perfil "posição socioeconômica elevada" indicam, como o nome já diz, melhores condições socioeconômicas, como maiores rendimentos, educação formal mais elevada, posse de veículo automotor e ocupações de maior prestígio social. O perfil “mulheres em baixa posição socioeconômica” é caracterizado pelas piores condições tanto em termos de mercado de trabalho, quanto familiares: grande proporção de mães solteiras, trabalhadoras domésticas, que, por alocarem muito tempo em casa, alocam menos tempo no trabalho. Com relação à comutação, o perfil é marcado por aquelas que nada comutam. 0 perfil "homens não metropolitanos" é caracterizado por baixa renda e também piores condições no mercado de trabalho, como ausência de carteira de trabalho assinada e elevada carga laboral diária (pode passar das 50 horas semanais). Entretanto, possuem motocicleta e/ou carro na residência e comutam até 30 minutos diariamente. Por fim, o perfil puro “homens metropolitanos" também é caracterizado por baixa renda (não tanto quanto o perfil anterior), indivíduos pretos, porém com melhores condições socioeconômicas, já que possuem carteira de trabalho assinada e trabalham até 50 horas por semana. 0 ponto negativo é que não possuem automóvel e comutam mais de 30 minutos pelo menos.

Os perfis puros abrangem $85,5 \%$ dos homens e $79,7 \%$ das mulheres. A maior proporção de brancos se encontra no perfil "posição socioeconômica elevada", sendo que 80,6\% 
pertencem a algum perfil puro. Entre os pretos, esse percentual é de $85,6 \%$, estando a maior parte no perfil puro “mulheres em baixa posição socioeconômica” (31,3\%). Entre os pardos, $85,2 \%$ pertencem a algum perfil puro, com a maior proporção no perfil "homens não metropolitanos". Portanto, os perfis puros fornecem elevado poder de descrever os padrões possíveis no mercado de trabalho, mas os perfis mistos também ajudam, principalmente, na tarefa de analisar o tempo comutado.

A distribuição espacial da população, como esperado, não se dá de forma aleatória. Resumindo, os mais pobres tendem a residir longe do centro e o oposto para os indivíduos em melhor situação financeira. Logo, os primeiros, além de privados monetariamente, em muitos casos tornam-se privados de tempo, pois se deslocam em maiores distâncias até o trabalho e, consequentemente, gastam mais tempo. Os perfis aqui apresentados apontam na mesma direção, pois trabalhadores considerados de pior status social são mais ligados a perfis de comutação mais elevada.

Além de ter sido encontrado o padrão esperado, ou seja pessoas de baixa posição socioeconômica são mais privadas de tempo, outro padrão interessante observado está no extremo oposto do grupo de comutação: entre os que nada comutam, é grande a preponderância de mulheres, pretas, com baixa escolaridade e baixo rendimento, ou seja, mulheres presas na origem. Ao mesmo tempo, para as que trabalham fora de casa, ter menor status social leva a maiores tempos comutados em comparação às mulheres em geral. Portanto, existe heterogeneidade neste contexto, que ficou clara a partir da modelagem aplicada.

Trabalhadores de elevada posição socioeconômica tendem a comutar, porém menos. Dado que possuem automóveis e, em geral, residem mais próximos dos trabalhos, é normal que estes ocupados gastem menos tempo no deslocamento diário. Se pensarmos em commuters que gastam muito tempo no trajeto diário, percebe-se que o problema é mais acentuado em áreas metropolitanas.

Como em qualquer análise sobre o mercado brasileiro, a importância da desigualdade social é levantada neste trabalho. Percebe-se que padrões de comutação são distintos para indivíduos de diferentes classes sociais, principalmente se estiverem em grandes centros urbanos. Apesar da aparente melhora socioeconômica no período analisado, tendência que pode ter sido revertida em parte com a recente crise, ainda há muita coisa a se fazer, principalmente pelo fato de ter havido crescimento da longa comutação. Como o fenômeno atinge mais fortemente os já privados de renda, cuidar para que eles não sejam também privados de tempo deve ser tarefa primordial em termos de políticas públicas, como melhoria de acesso, disponibilidade de diferentes meios de transporte, segurança nos trajetos, etc.

Finalizando, o presente trabalho almejou criar perfis que podem ser de utilidade para as análises nos ensaios subsequentes. É preciso ressaltar que não há neste estudo a busca por efeitos de causalidade, como, por exemplo, maior rendimento gera maior comutação, ou maior comutação leva a maiores rendimentos. 0 que se buscou foi identificar relações entre as características, sem detalhamento sobre direção de causalidade. 


\section{Referências}

BALTAR, Paulo. Crescimento da economia e mercado de trabalho no Brasil. Brasília: Instituto de Pesquisa Econômica Aplicada (Ipea), 2015. (Texto para Discussão, 2036).

BARROS, Ricardo Paes de et al. Inserção no mercado de trabalho: diferenças por sexo e conseqüências sobre o bem-estar. Brasília: Instituto de Pesquisa Econômica Aplicada (Ipea), 2001. (Texto para Discussão, n. 796).

BOJE, Amelie et al. Development perspectives for the City of Hamburg: migration, commuting, and specialization. Hamburg: Hamburg Institute of International Economics 2010 (HWWI Policy Papers, 1-23).

BRUECKNER, Jan K. Lectures on urban economics. Londres: MIT Press, 2011.

CAMAGNI, Roberto; GIBELLI, Maria Cristina; RIGAMONTI, Paolo. Urban mobility and urban form: the social and environmental costs of different patterns of urban expansion. Ecological Economics, v. 40, n. 2, p. 199-216, 2002.

CAMSTRA, Ronald. Household relocation and commuting distance in a gender perspective. Amsterdam, Netherlands: Universiteit van Amsterdam Postdoctorale Onderzoekersopleiding Demografie, Aug. 1994. (PDOD paper, n. 26).

CERQUEIRA, Cezar Augusto; SAWYER, Diana R. O. T. Tipologia dos estabelecimentos escolares brasileiros. Revista Brasileira de Estudos de População, v. 24, n. 1, p. 53-67, 2007.

CERVERO, Robert; DUNCAN, Michael. Walking, bicycling, and urban landscapes: evidence from the San Francisco bay area. American Journal of Public Health, v. 93, n. 9, p. 1478-1483, 2003.

CLARK, William A. V.; HUANG, Youqin; WITHERS, Suzanne. Does commuting distance matter? Commuting tolerance and residential change. Regional Science and Urban Economics, v. 33, n. 2, p. 199-221, 2003.

DOUTHITT, Robin A. "Time to do the chores?" Factoring home-production needs into measures of poverty. Journal of Family and Economic Issues, v. 21, n. 1, p. 7-22, 2000.

DUBIN, Robin. Commuting patterns and firm decentralization. Land Economics, v. 67, n. 1, p. 15-29, 1991.

FERREIRA, Francisco H. G. et al. Os determinantes da desigualdade de renda no Brasil: luta de classes ou heterogeneidade educacional? Rio de Janeiro: Pontifícia Universidade Católica do Rio de Janeiro, Departamento de Economia, 2000. (Texto para Discussão, n. 415).

FU, Shihe; VIARD, Brian. Commute costs and labor supply: evidence from a satellite campus. Munich: Munich Personal RePEc Archive, 2014. (MPRA Paper, n. 53740).

GUEDES, Gilvan R. et al. Identificabilidade e estabilidade dos parâmetros no método Grade of Membership (GoM): considerações metodológicas e práticas. Revista Brasileira de Estudos de Populacão, v. 27, n. 1, p. 21-33, jan./jun. 2010.

GIULIANO, Genevieve; SMALL, Kenneth A. Is the journey to work explained by urban structure? Urban Studies, v. 30, n. 9, p. 1485-1500, 1993.

GREENWALD, Michael; BOARNET, Marlon. Built environment as determinant of walking behavior: analyzing nonwork pedestrian travel in portland, oregon. Transportation Research Record: Journal of the Transportation Research Board, n. 1780, p. 33-41, 2001.

HAUSSMANN, Samantha; GOLGHER, André Braz. Shrinking gender wage gaps in the Brazilian labor market: an application of the apc approach. Nova Economia, v. 26, n. 2, p. 429-464, 2016. 
HADDAD, Eduardo A.; VIEIRA, Renato S. Mobilidade, acessibilidade e produtividade: nota sobre a valoração econômica do tempo de viagem na região metropolitana de São Paulo. Revista de Economia Contemporânea, v. 19, n. 3, 2015.

HENRIQUES, Ricardo. Desigualdade racial no Brasil: evolução das condições de vida na década de 90. Brasília, Ipea, 2001. (Texto para Discussão, n.807).

HOFFMANN, Rodolfo; LEONE, Eugênia Troncoso. Participação da mulher no mercado de trabalho e desigualdade da renda domiciliar per capita no Brasil: 1981-2002. Nova Economia, v. 14, n. 2, 2009.

HYMEL, Kent. Does traffic congestion reduce employment growth? Journal of Urban Economics, v. 65, n. 2, p. 127-135, 2009.

IBGE. Síntese de Indicadores. Pesquisa Nacional por Amostra de Domicílios - 2007. Rio de Janeiro, 2008.

LEME, Maria Carolina da Silva; WAJNMAN, Simone. Tendências de coorte nos diferenciais de rendimentos por sexo. In: HENRIQUES, Ricardo (org.). Desigualdade e pobreza no Brasil. Rio de Janeiro: Ipea, 2000. p. 251-270.

LEONE, Eugenia Troncoso; BALTAR, Paulo. Diferenças de rendimento do trabalho de homens e mulheres com educação superior nas metrópoles. Revista Brasileira de Estudos de População, v. 23, n. 2, p. 355-367, 2006.

LEONE, Eugenia Troncoso; BALTAR, Paulo. A mulher na recuperação recente do mercado de trabalho brasileiro. Revista Brasileira de Estudos de População, v. 25, n. 2, p. 233-249, 2008.

MADALOZZO, Regina. Occupational segregation and the gender wage gap in Brazil: an empirical analysis. Economia Aplicada, v. 14, n. 2, p. 147-168, 2010.

MADDEN, Janice Fanning. Why women work closer to home. Urban Studies, v. 18, n. 2, p. 181-194, 1981.

MANTON, Kenneth G.; TOLLEY, H. Dennis; WOODBURY, Max A. Statistical applications using fuzzy sets. New York: [s.n.], 1994.

MELO, Frederico L. B. Trajetórias no mercado de trabalho: perfis socioocupacionais de indivíduos e casais da Grande São Paulo. Tese (Doutorado) - Universidade Federal de Minas Gerais, Belo Horizonte, 2006.

PEREIRA, Rafael Henrique Moraes; SCHWANEN, Tim. Tempo de deslocamento casa-trabalho no Brasil (1992-2009): diferenças entre regiões metropolitanas, níveis de renda e sexo. Brasília: Instituto de Pesquisa Econômica Aplicada (Ipea), 2013. (Texto para Discussão, 1813).

ROUWENDAL, Jan; RIETVELD, Piet. Changes in commuting distances of Dutch households. Urban Studies, v. 31, n. 9, p. 1545-1557, 1994.

SAWYER, Diana Oya; LEITE, luri da Costa; ALEXANDRINO, Ricardo. Perfis de utilização de serviços de saúde no Brasil. Ciência \& Saúde Coletiva, v. 7, n. 4, p. 757-776, 2002.

SEPLAKI, Christopher; SMITH, Maureen; SINGER, Burton. Variation in living environments among community-dwelling elders. Princeton, NJ: Princeton University, Woodrow Wilson School of Public and International Affairs, Office of Population Research 2004. (Working Papers, 294).

SHEARMUR, Richard. Travel from home: an economic geography of commuting distances in montreal. Urban Geography, v. 27, n. 4, p. 330-359, 2006. 
SOARES, Cristiane; SABÓIA, Ana L. Tempo, trabalho e afazeres domésticos: um estudo com base nos dados da Pesquisa Nacional por Amostra de Domicílios de 2001 e 2005. Rio de Janeiro: IBGE, Coordenação de População e Indicadores Sociais, 2007.

STUTZER, Alois; FREY, Bruno S. Stress that doesn't pay: the commuting paradox. The Scandinavian Journal of Economics, v. 110, n. 2, p. 339-366, 2008.

TERRELL, George R.; SCOTT, David W. Oversmoothed nonparametric density estimates. Journal of the American Statistical Association, v. 80, n. 389, p. 209-214, 1985.

TOLLEY, H. Dennis; MANTON, Kenneth G. Large sample properties of estimates of a discrete grade of membership model. Annals of the Institute of Statistical Mathematics, v. 44, n. 1, p. 85-95, 1992.

VAN OMMEREN, Jos N.; GUTIÉRREZ-I-PUIGARNAU, Eva. Are workers with a long commute less productive? An empirical analysis of absenteeism. Regional Science and Urban Economics, v. 41, n. 1, p. 1-8, 2011.

VIANNA, Guilherme S. B.; YOUNG, Carlos Eduardo F. Em busca do tempo perdido: uma estimativa do produto perdido em trânsito no Brasil. Revista de Economia Contemporânea, v. 19, n. 3, p. 403-416, 2015.

WHITE, Michelle J. Sex differences in urban commuting patterns. The American Economic Review, v. 76, n. 2, p. 368-372, 1986.

WOODBURY, Max A.; MANTON, Kenneth G.; TOLLEY, H. Dennis. A general model for statistical analysis using fuzzy sets: sufficient conditions for identifiability and statistical properties. Information Sciences-Applications, v. 1, n. 3, p. 149-180, 1994.

WYLY, Elvin K. Containment and mismatch: gender differences in commuting in metropolitan labor markets. Urban Geography, v. 19, n. 5, p. 395-430, 1998.

\section{Sobre os autores}

Luiz Carlos Day Gama é doutor em economia pelo Centro de Desenvolvimento e Planejamento Regional (Cedeplar), Universidade Federal de Minas Gerais (UFMG). Professor titular I no Ibmec-MG.

André Braz Golgher é doutor em Demografia pelo Centro de Desenvolvimento e Planejamento Regional (Cedeplar), Universidade Federal de Minas Gerais (UFMG). Professor associado do Cedeplar e Face da Universidade Federal de Minas Gerais.

\section{Endereço para correspondência}

Luiz Carlos Day Gama

Rua João Gualberto Filho, 654, ap. 301, Sagrada Família

31030-410 - Belo Horizonte-MG, Brasil

André Braz Golgher

Rua Cristina, 1092, ap. 302, Santo Antônio

30330-228 - Belo Horizonte-MG, Brasil 


\begin{abstract}
Defining commuters profiles in Brazil

The aim of this article is the construction of typologies for Brazilian workers, especially regarding commuting time to work. Through the GoM (Grade of Membership) method, pure and mixed worker profiles in the Brazilian labor market were established, using data from 2009 and 2014 PNADs. Three basic characteristics marked those who spend a lot of time commuting: they are male, residents of metropolitan areas and have a low socioeconomic status. Analyzing the opposite end, profiles associated with workers who do not commute present a higher prevalence of women with low socioeconomic status. The spatial distribution of the population, as expected, is not random. In short, the poorest people tend to reside far from the town center and the opposite applies to individuals in a more favorable financial situation.
\end{abstract}

Keywords: GoM. Commuting. Profile.

\title{
Resumen
}

Definición de perfiles de commuters en Brasil

El propósito de este artículo es la construcción de tipologías para los trabajadores brasileños, en particular, con respecto al tiempo de trabajo. Mediante el método GoM (Grade of Membership), se establecieron perfiles puros y mixtos de trabajadores en el mercado laboral brasileño, utilizando datos de las PNAD de 2009 y 2014. Tres características básicas marcaron a aquellos trabajadores que pasan mucho tiempo viajando: son hombres, residen en áreas metropolitanas y tienen bajo nivel socioeconómico. Si se analiza el extremo opuesto, las mujeres en posición socioeconómica baja están más presentes en los perfiles caracterizados por una alta prevalencia de trabajadores que no viajan diariamente. La distribución espacial de la población, como se esperaba, no ocurre al azar. En resumen, los más pobres tienden a residir lejos del centro y lo contrario sucede con las personas que están en una mejor situación financiera.

Palabras clave: GoM. Conmutación. Perfil. 


\section{APÊNDICE A - Estimativas}

Tabela 1 - GoM considerando quatro perfis extremos Brasil - 2009/2014

\begin{tabular}{|c|c|c|c|c|c|c|c|c|c|c|c|}
\hline \multirow{2}{*}{ Variáveis } & \multirow{2}{*}{ Respostas } & \multicolumn{2}{|c|}{ Freq. marg. } & \multicolumn{4}{|c|}{ Lambdas } & \multicolumn{4}{|c|}{ Lambdas/freq. } \\
\hline & & Abs. & Rel. & 1 & 2 & 3 & 4 & 1 & 2 & 3 & 4 \\
\hline \multirow{5}{*}{ Comutação } & Nada & 25.160 & 11,21 & 0,075 & 0,183 & 0,08 & 0,081 & 0,67 & 1,64 & 0,71 & 0,72 \\
\hline & Até 30 minutos & 130.500 & 58,13 & 0,652 & 0,535 & 0,699 & 0,426 & 1,12 & 0,92 & 1,20 & 0,73 \\
\hline & $\begin{array}{l}\text { Mais de } 30 \text { min. até } \\
1 \text { hora }\end{array}$ & 48.327 & 21,53 & 0,2 & 0,196 & 0,16 & 0,327 & 0,93 & 0,91 & 0,74 & 1,52 \\
\hline & $\begin{array}{l}\text { Mais de } 1 \text { hora até } \\
2 \text { horas }\end{array}$ & 16.939 & 7,54 & 0,06 & 0,075 & 0,043 & 0,141 & 0,80 & 0,99 & 0,57 & 1,87 \\
\hline & Mais de 2 horas & 3.582 & 1,6 & 0,012 & 0,011 & 0,018 & 0,026 & 0,74 & 0,69 & 1,11 & 1,64 \\
\hline \multirow{2}{*}{ Sexo } & Masculino & 124.410 & 55,41 & 0,399 & 0 & 1 & 1 & 0,72 & 0,00 & 1,80 & 1,80 \\
\hline & Feminino & 100.098 & 44,59 & 0,601 & 1 & 0 & 0 & 1,35 & 2,24 & 0,00 & 0,00 \\
\hline \multirow{3}{*}{ Cor } & Branco & 104.571 & 46,58 & 0,73 & 0,37 & 0,393 & 0,383 & 1,57 & 0,79 & 0,84 & 0,82 \\
\hline & Preto & 21.327 & 9,5 & 0,04 & 0,117 & 0,087 & 0,141 & 0,42 & 1,23 & 0,92 & 1,49 \\
\hline & Pardo & 98.610 & 43,92 & 0,229 & 0,513 & 0,52 & 0,476 & 0,52 & 1,17 & 1,18 & 1,08 \\
\hline \multirow{5}{*}{$\begin{array}{l}\text { Grupos } \\
\text { de idade }\end{array}$} & $21-25$ & 28.290 & 12,6 & 0,136 & 0,109 & 0,132 & 0,129 & 1,08 & 0,87 & 1,05 & 1,03 \\
\hline & $26-30$ & 33.865 & 15,08 & 0,173 & 0,137 & 0,146 & 0,151 & 1,15 & 0,91 & 0,97 & 1,00 \\
\hline & $31-40$ & 66.445 & 29,6 & 0,293 & 0,309 & 0,291 & 0,287 & 0,99 & 1,04 & 0,98 & 0,97 \\
\hline & $41-50$ & 55.471 & 24,71 & 0,231 & 0,265 & 0,241 & 0,249 & 0,93 & 1,07 & 0,97 & 1,01 \\
\hline & $51-65$ & 40.437 & 18,01 & 0,167 & 0,179 & 0,19 & 0,185 & 0,93 & 1,00 & 1,05 & 1,03 \\
\hline \multirow{2}{*}{$\begin{array}{l}\text { Frequenta } \\
\text { escola? }\end{array}$} & Não & 208.572 & 92,9 & 0,792 & 0,954 & 1 & 0,968 & 0,85 & 1,03 & 1,08 & 1,04 \\
\hline & Sim & 15.936 & 7,1 & 0,208 & 0,046 & 0 & 0,032 & 2,93 & 0,65 & 0 & 0,45 \\
\hline \multirow{7}{*}{$\begin{array}{l}\text { Nível de } \\
\text { instrução }\end{array}$} & Sem instrução & 10.174 & 4,53 & 0 & 0,05 & 0,082 & 0,044 & 0,00 & 1,10 & 1,81 & 0,97 \\
\hline & $\begin{array}{l}\text { Fundamental } \\
\text { incompleto ou } \\
\text { equivalente }\end{array}$ & 56.809 & 25,3 & 0 & 0,32 & 0,384 & 0,291 & 0,00 & 1,26 & 1,52 & 1,15 \\
\hline & $\begin{array}{l}\text { Fundamental } \\
\text { completo ou } \\
\text { equivalente }\end{array}$ & 21.852 & 9,73 & 0,006 & 0,123 & 0,124 & 0,137 & 0,06 & 1,26 & 1,27 & 1,40 \\
\hline & $\begin{array}{l}\text { Médio incompleto ou } \\
\text { equivalente }\end{array}$ & 12.938 & 5,76 & 0,006 & 0,073 & 0,073 & 0,077 & 0,11 & 1,27 & 1,26 & 1,34 \\
\hline & $\begin{array}{l}\text { Médio completo ou } \\
\text { equivalente }\end{array}$ & 73.185 & 32,6 & 0,187 & 0,398 & 0,315 & 0,405 & 0,57 & 1,22 & 0,97 & 1,24 \\
\hline & $\begin{array}{l}\text { Superior incompleto } \\
\text { ou equivalente }\end{array}$ & 13.947 & 6,21 & 0,203 & 0,017 & 0,009 & 0,026 & 3,27 & 0,28 & 0,15 & 0,41 \\
\hline & Superior completo & 35.603 & 15,86 & 0,621 & 0,012 & 0,008 & 0,014 & 3,92 & 0,08 & 0,05 & 0,09 \\
\hline \multirow{4}{*}{ Tipo de família } & Casal sem filhos & 35.723 & 15,91 & 0,198 & 0,129 & 0,16 & 0,156 & 1,24 & 0,81 & 1,00 & 0,98 \\
\hline & Casal com filhos & 110.203 & 49,09 & 0,501 & 0,388 & 0,561 & 0,539 & 1,02 & 0,79 & 1,14 & 1,10 \\
\hline & Mãe e filhos apenas & 33.555 & 14,95 & 0,123 & 0,302 & 0,058 & 0,076 & 0,82 & 2,02 & 0,39 & 0,51 \\
\hline & $\begin{array}{l}\text { Outros tipos de } \\
\text { família }\end{array}$ & 45.027 & 20,06 & 0,178 & 0,182 & 0,222 & 0,229 & 0,89 & 0,91 & 1,11 & 1,14 \\
\hline
\end{tabular}


(continuação)

\begin{tabular}{|c|c|c|c|c|c|c|c|c|c|c|c|}
\hline & $\begin{array}{l}\text { Empregados } \\
\text { com carteira de } \\
\text { trabalho assinada }\end{array}$ & 98.032 & 43,67 & 0,425 & 0,326 & 0,456 & 0,594 & 0,97 & 0,75 & 1,04 & 1,36 \\
\hline & $\begin{array}{l}\text { Militares e } \\
\text { funcionários } \\
\text { públicos estatutários }\end{array}$ & 22.027 & 9,81 & 0,276 & 0,051 & 0,04 & 0,029 & 2,82 & 0,52 & 0,41 & 0,30 \\
\hline \multirow[t]{9}{*}{$\begin{array}{l}\text { Posição } \\
\text { na ocupação }\end{array}$} & $\begin{array}{l}\text { Outros empregados } \\
\text { sem carteira de } \\
\text { trabalho assinada }\end{array}$ & 29.823 & 13,28 & 0,115 & 0,117 & 0,178 & 0,118 & 0,87 & 0,88 & 1,34 & 0,89 \\
\hline & $\begin{array}{l}\text { Trabalhador } \\
\text { doméstico }\end{array}$ & 18.272 & 8,14 & 0 & 0,27 & 0,002 & 0,007 & 0,00 & 3,32 & 0,03 & 0,09 \\
\hline & Conta própria & 45.754 & 20,38 & 0,081 & 0,226 & 0,273 & 0,227 & 0,40 & 1,11 & 1,34 & 1,12 \\
\hline & Empregadores & 10.600 & 4,72 & 0,115 & 0,003 & 0,051 & 0,025 & 2,44 & 0,06 & 1,08 & 0,54 \\
\hline & Dirigentes em geral & 14.199 & 6,32 & 0,183 & 0,006 & 0,042 & 0,03 & 2,89 & 0,09 & 0,66 & 0,48 \\
\hline & $\begin{array}{l}\text { Profissionais das } \\
\text { ciências e das artes }\end{array}$ & 23.406 & 10,43 & 0,407 & 0,014 & 0,003 & 0,005 & 3,90 & 0,13 & 0,03 & 0,05 \\
\hline & $\begin{array}{l}\text { Técnicos de nível } \\
\text { médio }\end{array}$ & 18.968 & 8,45 & 0,159 & 0,058 & 0,052 & 0,077 & 1,89 & 0,69 & 0,61 & 0,91 \\
\hline & $\begin{array}{l}\text { Trabalhadores } \\
\text { de serviços } \\
\text { administrativos }\end{array}$ & 24.044 & 10,71 & 0,191 & 0,112 & 0,043 & 0,084 & 1,78 & 1,05 & 0,40 & 0,78 \\
\hline & $\begin{array}{l}\text { Trabalhadores dos } \\
\text { serviços }\end{array}$ & 51.915 & 23,12 & 0,012 & 0,538 & 0,123 & 0,191 & 0,05 & 2,33 & 0,53 & 0,82 \\
\hline \multirow[t]{6}{*}{$\begin{array}{l}\text { Grupo } \\
\text { ocupacional }\end{array}$} & $\begin{array}{l}\text { Vendedores } \\
\text { e prestadores } \\
\text { de serviço do } \\
\text { comércio }\end{array}$ & 22.673 & 10,1 & 0,033 & 0,156 & 0,096 & 0,108 & 0,33 & 1,54 & 0,95 & 1,07 \\
\hline & $\begin{array}{l}\text { Trabalhadores } \\
\text { agrícolas }\end{array}$ & 7.919 & 3,53 & 0,001 & 0,013 & 0,111 & 0,008 & 0,02 & 0,36 & 3,13 & 0,22 \\
\hline & $\begin{array}{l}\text { Trabalhadores } \\
\text { da produção de } \\
\text { bens e serviços } \\
\text { e de reparação e } \\
\text { manutenção }\end{array}$ & 58.832 & 26,2 & 0,003 & 0,1 & 0,52 & 0,479 & 0,01 & 0,38 & 1,99 & 1,83 \\
\hline & $\begin{array}{l}\text { Membros das Forças } \\
\text { Armadas e auxiliares }\end{array}$ & 2.552 & 1,14 & 0,026 & 0 & 0,009 & 0,014 & 2,24 & 0 & 0,79 & 1,27 \\
\hline & Até $\mathrm{R} \$ 400$ & 45.434 & 20,24 & 0 & 0,277 & 0,286 & 0,228 & 0,00 & 1,37 & 1,41 & 1,13 \\
\hline & $\begin{array}{l}\text { Acima de } R \$ 400 \text { até } \\
R \$ 650\end{array}$ & 46.496 & 20,71 & 0,021 & 0,293 & 0,247 & 0,252 & 0,10 & 1,41 & 1,19 & 1,22 \\
\hline \multirow[t]{5}{*}{$\begin{array}{l}\text { Faixa de } \\
\text { Renda }\end{array}$} & $\begin{array}{l}\text { Acima de } R \$ 650 \text { até } \\
R \$ 950\end{array}$ & 42.510 & 18,93 & 0,088 & 0,232 & 0,212 & 0,219 & 0,46 & 1,23 & 1,12 & 1,16 \\
\hline & $\begin{array}{l}\text { Acima de } R \$ 950 \text { até } \\
R \$ 1.600\end{array}$ & 44.454 & 19,8 & 0,243 & 0,165 & 0,184 & 0,211 & 1,23 & 0,84 & 0,93 & 1,07 \\
\hline & Acima de $\mathrm{R} \$ 1.600$ & 45.614 & 20,32 & 0,658 & 0,032 & 0,07 & 0,084 & 3,24 & 0,16 & 0,34 & 0,41 \\
\hline & Até 35 horas & 41.003 & 18,26 & 0,189 & 0,334 & 0,088 & 0,075 & 1,04 & 1,83 & 0,48 & 0,41 \\
\hline & $\begin{array}{l}\text { Acima de } 35 \text { até } 40 \\
\text { horas }\end{array}$ & 75.125 & 33,46 & 0,473 & 0,269 & 0,285 & 0,332 & 1,41 & 0,8 & 0,85 & 0,99 \\
\hline \multirow[t]{3}{*}{$\begin{array}{l}\text { Horas } \\
\text { trabalhadas }\end{array}$} & $\begin{array}{l}\text { Acima de } 40 \text { até } 45 \\
\text { horas }\end{array}$ & 46.391 & 20,66 & 0,149 & 0,174 & 0,262 & 0,253 & 0,72 & 0,84 & 1,27 & 1,23 \\
\hline & $\begin{array}{l}\text { Acima de } 45 \text { até } 49 \\
\text { horas }\end{array}$ & 25.844 & 11,51 & 0,042 & 0,113 & 0,152 & 0,159 & 0,36 & 0,98 & 1,32 & 1,38 \\
\hline & 50 ou mais horas & 36.145 & 16,1 & 0,147 & 0,111 & 0,215 & 0,182 & 0,91 & 0,69 & 1,33 & 1,13 \\
\hline
\end{tabular}

(continua) 
(continuação)

\begin{tabular}{|c|c|c|c|c|c|c|c|c|c|c|c|}
\hline & Nada & 66.990 & 29,84 & 0,264 & 0,032 & 0,512 & 0,452 & 0,89 & 0,11 & 1,72 & 1,52 \\
\hline & $\begin{array}{l}\text { Acima de } 0 \text { até } 5 \\
\text { horas }\end{array}$ & 27.840 & 12,4 & 0,163 & 0,036 & 0,156 & 0,167 & 1,31 & 0,29 & 1,26 & 1,34 \\
\hline \multirow[t]{4}{*}{$\begin{array}{l}\text { Horas } \\
\text { domésticas }\end{array}$} & $\begin{array}{l}\text { Acima de } 5 \text { até } 10 \\
\text { horas }\end{array}$ & 40.535 & 18,06 & 0,22 & 0,125 & 0,189 & 0,204 & 1,22 & 0,69 & 1,05 & 1,13 \\
\hline & $\begin{array}{l}\text { Acima de } 10 \text { abaixo } \\
\text { de } 20 \text { horas }\end{array}$ & 30.525 & 13,6 & 0,147 & 0,188 & 0,091 & 0,106 & 1,08 & 1,38 & 0,67 & 0,78 \\
\hline & 20 horas ou mais & 58.618 & 26,11 & 0,199 & 0,623 & 0,053 & 0,074 & 0,76 & 2,39 & 0,2 & 0,28 \\
\hline & Não possui & 90.905 & 40,49 & 0,067 & 0,606 & 0,396 & 0,534 & 0,16 & 1,5 & 0,98 & 1,32 \\
\hline \multirow{3}{*}{$\begin{array}{l}\text { Posse de } \\
\text { automóvel }\end{array}$} & Tem carro & 86.287 & 38,43 & 0,754 & 0,207 & 0,279 & 0,342 & 1,96 & 0,54 & 0,73 & 0,89 \\
\hline & Tem motocicleta & 24.798 & 11,05 & 0,035 & 0,123 & 0,191 & 0,073 & 0,32 & 1,11 & 1,73 & 0,66 \\
\hline & $\begin{array}{l}\text { Tem carro e } \\
\text { motocicleta }\end{array}$ & 22.518 & 10,03 & 0,146 & 0,064 & 0,134 & 0,05 & 1,46 & 0,64 & 1,34 & 0,5 \\
\hline \multirow{2}{*}{$\begin{array}{l}\text { Região } \\
\text { metropolitana }\end{array}$} & Não & 127.328 & 56,71 & 0,521 & 0,577 & 1 & 0 & 0,92 & 1,02 & 1,76 & 0 \\
\hline & Sim & 97.180 & 43,29 & 0,479 & 0,423 & 0 & 1 & 1,11 & 0,98 & 0 & 2,31 \\
\hline
\end{tabular}

Fonte: IBGE. Pesquisa Nacional por Amostra de Domicílios (PNAD) 2009 e 2014. Elaboração dos autores. 